\title{
The Atf1 transcription factor is a target for the Sty1 stress-activated MAP kinase pathway in fission yeast
}

\author{
Marc G. Wilkinson, ${ }^{1,4}$ Michael Samuels, ${ }^{2,4}$ Tadayuki Takeda, $^{2,5}$ W. Mark Toone, ${ }^{2}$ Jia-Ching Shieh, $^{1}$ \\ Takashi Toda, ${ }^{3}$ Jonathan B.A. Millar, ${ }^{1,6}$ and Nic Jones ${ }^{2,6}$ \\ ${ }^{1}$ Division of Yeast Genetics, National Institute for Medical Research, London NW7 1AA UK; ${ }^{2}$ Laboratory of Gene \\ Regulation and ${ }^{3}$ Laboratory of Cell Regulation, Imperial Cancer Research Fund, London WC2A 3PX UK
}

The $a t f 1^{+}$gene of Schizosaccharomyces pombe encodes a bZIP transcription factor with strong homology to the mammalian factor ATF-2. ATF-2 is regulated through phosphorylation in mammalian cells by the stress-activated mitogen-activated protein (MAP) kinases SAPK/JNK and p38. We show here that the fission yeast Atf1 factor is also regulated by a stress-activated kinase, Sty1. The Sty1 kinase is stimulated by a variety of different stress conditions including osmotic and oxidative stress and heat shock. Deletion of the atf $1^{+}$ gene results in many, but not all, of the phenotypes associated with loss of Sty1, including sensitivity to environmental stress and inability to undergo sexual conjugation. Furthermore, we identify a number of target genes that are induced rapidly in a manner dependent upon both the Sty1 kinase and the Atf1 transcription factor. These genes include $\mathrm{gpdi}^{+}$, which is important for the response of cells to osmotic stress, the catalase gene $\lambda$ important for cells to combat oxidative stress, and $p y p 2^{+}$, which encodes a tyrosine-specific MAP kinase phosphatase. Induction of Pyp2 by Atf1 is direct in that it does not require de novo protein synthesis and results in a negative feedback loop that serves to control signaling through the Sty1/Wis1 pathway. We show that Atf1 associates stably and is phosphorylated by the Styl kinase in vitro. Taken together, these results indicate that the interaction between Atf1 and Sty1 is direct. These findings highlight a remarkable level of conservation in transcriptional control by stress-activated MAP kinase pathways between fission yeast and mammalian cells.

[Key Words: S. pombe; stess response; MAP kinase; Atfl transcription factor]

Received June 26, 1996; revised version accepted August 2, 1996.

The mitogen-activated protein kinase (MAPK) signaling pathways are critical for the response of cells to changes in their external environment (for review, see Marshall 1994; Herskowitz 1995; Wasiewicz and Cooper 1995; Treisman 1996). They serve to transduce signals generated at the cell surface to the nucleus, where changes in the gene expression pattern of the cell occur. The responses that follow can be varied, including alterations in the proliferation or differentiation state of the cell or changes in protective mechanisms that serve to combat different stress conditions. At the heart of such signaling pathways lies the MAPK module, a kinase cascade that culminates in the activation of a MAPK through phosphorylation by a MAPK kinase (MAPKK), which itself is phosphorylated and activated by a MAPKK kinase (MAPKKK). Such MAPK cascades are evolutionarily conserved, having been identified and characterized in numerous organisms ranging from yeast to mammals $\mid \mathrm{Am}$ -

\footnotetext{
${ }^{4}$ These authors contributed equally to this paper.

${ }^{5}$ Present address: Institute of Medical Science, University of Tokyo, Tokyo, 108 Japan.

${ }^{6}$ Corresponding authors.
}

merer 1994; Herskowitz 1995; Wasiewicz and Cooper 1995). In addition, it is clear that multiple independently acting cascades can function in any one cell. The most striking example of such multiplicity can be found in the budding yeast Saccharomyces cerevisiae, where at least five distinct pathways have been identified that serve to control very different physiological processes such as sporulation, mating, cell wall biosynthesis and response to osmotic stress (Ammerer 1994; Herskowitz 1995; Levin and Errede 1995). In mammalian cells three distinct pathways have been identified, although there are clear indications that more pathways do exist. The bestcharacterized pathway activates the extra-cellular-signal-regulated kinases ERK1 and ERK2 in response to a variety of growth factors and mitogens and has been shown to be involved in the control of cell proliferation and differentiation (Marshall 1994). The physiological function of the other two pathways that activate the MAPKs JNK/SAPK and p38 kinase is less well understood. Both pathways are activated by a variety of stress conditions (e.g., osmotic stress and UV radiation) as well as inflammatory cytokines (e.g., interleukin-1 and tumor necrosis factor| and consequently have been implicated 
in playing a role in the response of cells to stress and in T-cell activation and inflammation (Davies 1994; Waskiewicz and Cooper 1995). The p38 kinase is related highly to the HOGl kinase of S. cerevisiae $157 \%$ identity; Han et al. 1994; Freshney et al. 1994; Lee et al. 1994; Rouse et al. 1994), which functions in the response of cells to high extracellular osmolarity; thus, deletion of HOG1 results in cells sensitive to osmotic stress (Brewster et al. 1993). The conservation that is evident from the structural similarity between these stress-activated MAPKs is strikingly clear from the finding that HOG1 can be replaced functionally by p38 (Han et al. 1994).

A Hogl homolog from Schizosaccharomyces pombe, Styl, has been described recently (Millar et al. 1995), and is also known as Spcl (Shiozaki and Russell 1995) and Phhl (Kato et al. 1996). It is phosphorylated and activated by the Wisl MAPKK. This pathway is involved intimately in the stress response of the cell; it is activated by a variety of stress conditions including osmotic stress, and deletion of either wis 1 or styl results in increased sensitivity to heat and high osmotic conditions (Warbrick and Fantes 1991; Millar et al. 1995; Shiozaki and Russell 1995; Degols et al. 1996; Kato et al. 1996). However, the pathway has additional physiological roles. Both wis 1 or sty 1 deletion mutants are profoundly sterile, indicating that signaling through this pathway is required for one or more steps in the sexual differentiation pathway. In addition, the Sty $1 /$ Wisl pathway plays a role in the control of mitotic initiation, because cells deleted for wis1 or sty1 are considerably longer at cell division than wild-type cells, and mutations in the pathway display strong genetic interactions with mutations in other genes such as $c d c 25^{+}$that result in mitotic defects (Millar et al. 1992, 1995; Shiozaki and Russell 1995). However, how the Styl kinase mediates these different activities is at present unknown and will depend absolutely upon the identification of relevant Styl phosphorylation targets.

Because the activation of MAPK pathways results in changes in the transcriptional pattern of the cell, a key step in understanding their function is the characterization of transcription factors whose activity is modulated by MAPK phosphorylation. In mammalian cells, a number of factors now have been identified (for review, see Treisman 1996). Elk-1, a member of the TCF family of ETS domain proteins that synergizes with the serum response factor (SRF) to mediate activation of certain immediate early genes such as the c-fos gene, was demonstrated to be regulated through phosphorylation by ERK1/2 (Gille et al. 1992; Marais et al. 1993). More recently, however, it has been shown to be a target of JNK/ SAPK and p38 (Gille et al. 1995; Whitmarsh et al. 1995; Zinck et al. 1995), indicating that all three mammalian pathways can converge at a common factor and presumably, therefore, common promoters. Other targets show a greater degree of specificity. The cJun factor is regulated by JNK/SAPK (Hibi et al. 1993; Derijard et al. 1994; Kyriakis et al. 1994) but not by ERK1/2 or p38, whereas ATF-2 is phosphorylated and regulated by both JNK/ SAPK /Gupta et al. 1995; Livingstone et al. 1995; van
Dam et al. 1995) and p38 (Raingeaud et al. 1995). In all three cases phosphorylation results in an increase in the activation potential of the factor, although the mechanisms that underlie these increases are not understood.

A central question concerning the conservation of the MAPK signaling pathways is whether it is restricted to the MAPK module or whether it extends downstream of the pathway to common transcription factors and target genes that are regulated by the pathways. Structural homologs of ATF-2 and cJun have been identified in $S$. pombe. The atf $1^{+}$gene encodes a factor containing a bZip domain at its carboxyl terminus that is related closely to the bZip domain of ATF-2 (Takeda et al. 1995). Furthermore, it has a DNA-binding specificity that is similar to ATF-2 (TG/TACGTC/AC/A) and can activate transcription from a reporter containing ATF sites within its promoter. Although disruption of the atf $1^{+}$ gene is not lethal, it does result in rapid cell death in stationary phase as well as failure in the initation of the sexual differentiation pathway. Here we show that Atfl is downstream of the Wis1/Styl pathway and that the expression of multiple targets shown previously to be dependent upon Styl and/or Wis 1 is also dependent upon Atf1. One such target is $p y p 2^{+}$, which encodes a tyrosine-specific phosphatase that dephosphorylates and hence inactivates Styl. Therefore, through the Atfl factor, a negative feedback loop operates to regulate the extent of signaling through this pathway. Furthermore, we show that the link between Styl and Atfl is direct; Atf 1 binds specifically to, and is phosphorylated by, the Styl kinase. These results demonstrate remarkable structural and functional conservation in the stress response between mammalian cells and fission yeast.

\section{Results}

Disruption of either atf $1^{+}$or wis $1^{+}$results in sensitivity to osmotic stress and suppression of uncontrolled meiosis driven by mutation in pat $1^{+}$

We had shown previously that disruption of the at $f 1^{+}$ gene resulted in sterility and loss of viability in stationary phase (Takeda et al. 1995). These properties are shared by mutants disrupted in either sty $1^{+}$(Millar et al. 1995; Shiozaki and Russell 1995; Kato et al. 1996) or wis $1^{+}$(Warbrick and Fantes 1991), indicating the possibility that the Atfl factor might be a downstream target of the Wisl/Styl signaling pathway. Activation of this pathway can be triggered by a variety of conditions, including an increase in osmolarity, heat shock, UV radiation, oxidative stress, and the addition of DNA damaging agents such as bleomycin (Millar et al. 1995; Shiozaki and Russell 1995; Degols et al. 1996; Kato et al. 1996). This suggests that the pathway is vital for the protective response of cells to such stress conditions, supported by the finding that disruption of sty $1^{+}$or wis $1^{+}$results in hypersensitivity to high extracellular osmotic conditions. If Atf 1 is an essential downstream target of the pathway, then its absence should also result in stress hypersensitivity. As shown in Figure 1A, this 
A
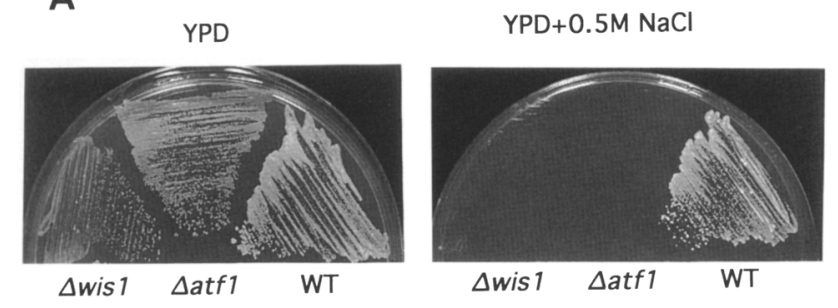

B
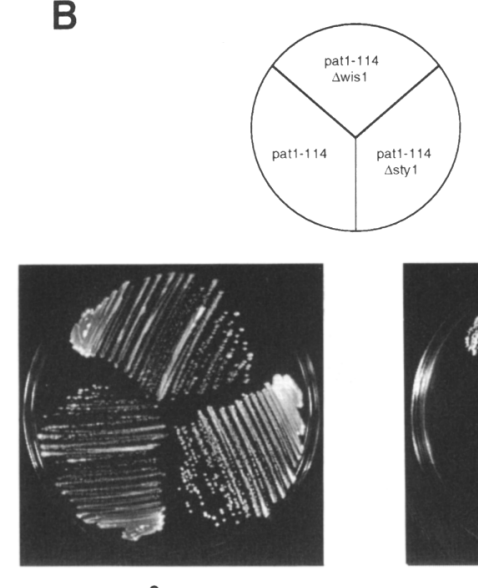

${ }^{25^{\circ} \mathrm{C}}$

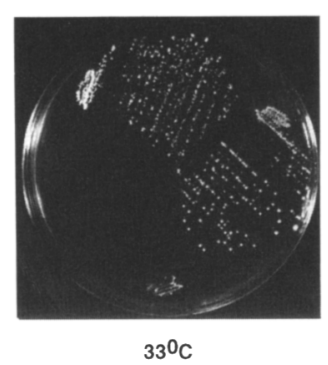

Figure 1. Overlapping phenotypes caused by loss of Atfl or components of the Styl/Wisl signaling pathway. (A) Atfl is required for resistance to osmotic stress. Wild-type (HM123), $\Delta$ wis1 (JM544) and $\Delta a t f 1$ (NT146) cells were grown on YPD plates and then streaked onto either YPD medium alone or YPD containing $0.5 \mathrm{M} \mathrm{NaCl}$ and incubated at $30^{\circ} \mathrm{C}$ for 3 days. $(B)$ Deletion of wis1 or sty1 rescues the pat1-114 phenotype. pat1114 (JM836) or $\Delta$ wis1 pat1-114 (JM1266) or $\Delta$ sty1 pat1-114 (JM1267) cells were plated and streaked on rich medium at either $25^{\circ} \mathrm{C}$ (left) or $33^{\circ} \mathrm{C}$ (right).

was found to be the case for osmotic stress. Unlike wildtype cells that proliferate normally on medium containing $0.5 \mathrm{M} \mathrm{NaCl}$, both $\Delta a t f 1$ and $\Delta$ wis1 cells fail to do so. An identical result was observed on medium containing $1.2 \mathrm{M}$ sorbitol (data not shown).

Conversely, it might be expected that phenotypes ascribed to loss of Atf1 would also be seen in $\Delta$ wis1 or $\Delta$ sty 1 cells. We had shown previously that the $\Delta$ pat 1 phenotype could be suppressed by atf $1^{+}$inactivation (Takeda et al. 1995). The pat $1^{+}$gene encodes a kinase that negatively regulates entry into meiosis. Strains carrying a temperature-sensitive allele of $\mathrm{pat}^{+}$can initiate meiosis at the restrictive temperature in haploid cells (Iino and Yamamoto 1985a); as a result of this meiotic induction, cells fail to grow at $33^{\circ} \mathrm{C}$ (Iino and Yamamoto 1985b). However, as shown in Figure 1B, both pat1-114 $\Delta$ wis1 and pat1-114 $\Delta$ sty1 cells grew well at this temperature on rich medium, indicating that mutation of wis $1^{+}$and $\operatorname{sty} 1^{+}$, like mutation of at $f 1^{+}$, suppresses the phenotype that results from Patl inactivation. We also showed previously that suppression of the pat1-114 phenotype by $\Delta a t f 1$ was influenced by cAMP levels (Takeda et al. 1995); suppression on minimal medium was obtained in the presence of moderate to high levels but not on low levels of cAMP and caffeine. Similar observations were made with pat1-114 $\Delta$ sty1 cells (data not shown).

Mutations in either sty1 or wis 1 result in a delay in the timing of mitotic initiation (Warbrick and Fantes 1991; Millar et al. 1995; Shiozaki and Russell 1995). This phenotype is not shared by $\Delta a t f 1$ cells. As the results in Table 1 demonstrate, unlike $\Delta s t y 1$ or $\Delta$ wis 1 cells, $\Delta a t f 1$ cells display no defect in the timing of mitotic initiation, their cell size at division being close to that seen with wild-type cells. Furthermore, mutants in either sty1 or wis1 are synthetically lethal with $c d c 25-22$ cells that express a temperature-sensitive mutant of the Cdc $25 \mathrm{mi}$ totic inducer. No such synthetic interaction was observed between $\Delta a t f 1$ and $c d c 25-22$ (Table 1).

\section{Transcription from an ATF-site-dependent reporter is regulated by osmotic stress}

We have described previously a reporter gene containing three tandem copies of the E4 ATF-binding site upstream of the basic promoter of the fission yeast p25 gene (Takeda et al. 1995). Expression of this reporter was shown to be dependent upon the Atfl factor. Since the results described above indicated that Atfl could be a downstream target of the Styl/Wisl pathway, we asked whether expression of the reporter could be stimulated by an increase in osmolarity. As shown in Figure 2A, a time-dependent 2.5- to 3-fold increase was observed following treatment with $1.2 \mathrm{M}$ sorbitol; expression from a control reporter that lacked the ATF sites was unaffected. This increase was abolished in $\Delta$ wis 1 cells and enhanced in $\Delta p y p 1$ cells (Fig. 2B). Pyp1, like Pyp2, is a tyrosine-specific phosphatase that can inhibit the Styl MAPK pathway (Millar et al. 1995; Shiozaki and Russell 1995; Kato et al. 1996). Tyrosine phosphorylation of Styl kinase is increased in $\Delta p y p 1$ cells. The results show that the expression of the reporter can be controlled by signaling through the Styl pathway.

Table 1. Datfl cells do not have a cell size at division defect

\begin{tabular}{lcc}
\hline Strain & $\begin{array}{l}\text { Temperature } \\
\left({ }^{\circ} \mathrm{C}\right)\end{array}$ & $\begin{array}{c}\text { Cell size at } \\
\text { division }(\mu \mathrm{m})\end{array}$ \\
\hline wt & 30 & $14.2 \pm 0.3$ \\
cdc25-22 & 26 & $19.3 \pm 0.3$ \\
wis1::ura4 & 30 & $23.4 \pm 1.3$ \\
sty1::ura4 & 30 & $23.2 \pm 1.6$ \\
atf1::ura4 & 30 & $13.1 \pm 1.6$ \\
cdc25-22 wis1::ura4 & 26 & $\mathrm{cdc}^{-}$ \\
cdc25-22 sty1::ura4 & 26 & $\mathrm{cdc}^{-}$ \\
cdc25-22 atf1::ura4 & 26 & $18.1 \pm 1.6$ \\
\hline
\end{tabular}

Loss of atf1 does not delay the timing of mitosis.

${ }^{a}$ Cell size measurements of septated cells grown in liquid synthetic minimal medium (EMM). (cdc) Cell division cycle phenotype. Measurements were the mean of 30 individual determinations ( \pm S.D.). 
A

Figure 2. Atfl activity is regulated by environmental stress. (A) Wild-type cells containing either a promoter-less $l a c Z$ reporter (pLacZ; stippled bars) or a $1 a c Z$ reporter fused to an Atfldependent promoter (pATFLacZ; solid bars) (Takeda et al. 1995) were assayed for $\beta$-galactosidase activity following growth in minimal medium containing $1.2 \mathrm{M}$ sorbitol for the indicated times. (B) Wild-type (HM123), Awis1 (JM544), or $\Delta p y p 1$ (NT132) cells containing a $1 a c Z$ reporter fused to an ATF-dependent promoter (Takeda et al. 1995) were grown for $3 \mathrm{hr}$ in minimal medium (stippled bars) or minimal medium containing $1.2 \mathrm{M}$ sorbitol (solid bars), and subsequently assayed for $\beta$-galactosidase activity.

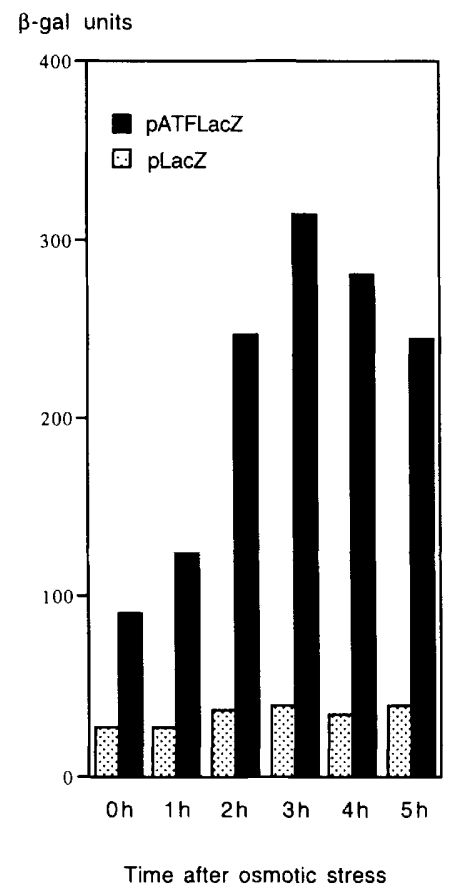

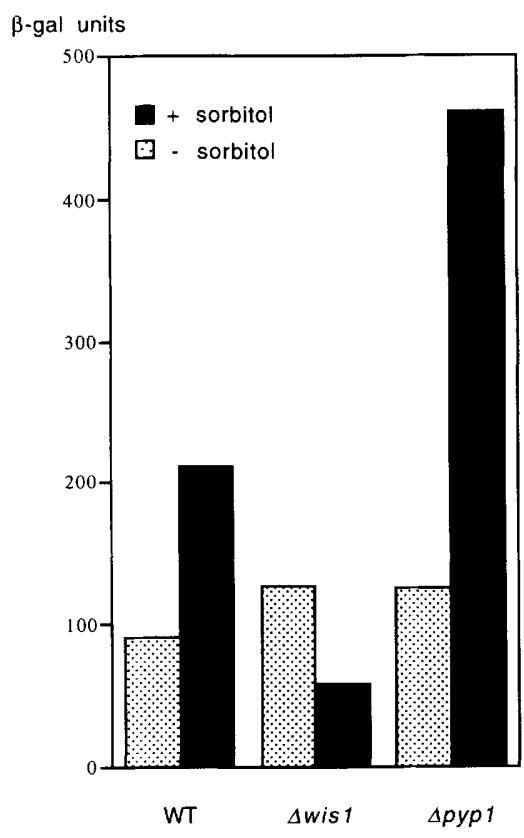

Atf1 is required for the induction of pyp2 and mediates feedback inhibition of the Sty 1 MAPK in response to osmotic stress

Previous results demonstrated that transcription of the pyp $2^{+}$gene encoding a tyrosine-specific phosphatase was induced by increased extracellular osmolarity in a Sty1- and Wis1-dependent manner (Millar et al. 1995). Furthermore, this induction results in the initiation of a negative feedback loop; the newly synthesized Pyp2 dephosphorylates, and hence inactivates, the Styl kinase, resulting in transient tyrosine phosphorylation of Styl following its activation. In support for such a regulatory pathway, we show in Figure $3 \mathrm{~A}$ that the loss of Stylassociated phosphotyrosine following prolonged exposure of cells to osmotic stress is dependent on protein synthesis. When cells are pretreated with cycloheximide and then challenged with $0.9 \mathrm{M} \mathrm{KCl}$, tyrosine phosphorylation of Styl remains high for up to $3 \mathrm{hr}$. Importantly, however, such treatment did not prevent the induction of pyp2 mRNA; indeed, elevated levels of $p y p 2^{+}$transcription persisted over the time course of the experiment, whereas in wild-type cells, induction was transient (Fig. 3B). These results strongly suggest that the induction of $p y p 2^{+}$mRNA by activation of the Styl MAP kinase occurs via a pre-existing transcription factor acting on the $p y p 2^{+}$promoter.

We considered Atfl to be a strong candidate for such a factor. Not only was there an overlap in phenotypes that derive from mutations in atf $1^{+}$or in the Sty1/Wis 1 pathway, but the activity of Atfl as measured by the reporter assay appeared to be regulated by the Styl kinase. Therefore, we asked whether the induction of pyp $2^{+}$transcription by stress required Atfl. Log-phase cultures of wild-type cells or $\Delta a t f 1$ cells were treated with $0.9 \mathrm{M} \mathrm{KCl}$ and the expression of pyp 2 was observed over time. As shown in Figure 4A, the large stimulation of pyp 2 mRNA expression was completely lost in $\Delta a t f 1$ cells. Reintroduction of the atf $1^{+}$gene expressed from the thiamine-repressible $n m t l$ promoter efficiently reversed this loss. Similar results were observed when wild-type or $\Delta a t f 1$ cells were shocked with $1.2 \mathrm{M}$ sorbitol, $1 \mathrm{mM} \mathrm{H}_{2} \mathrm{O}_{2}$, or elevated temperature /data not shown). All of these conditions stimulate the Styl pathway (Degols et al. 1996; Kato et al. 1996; M.G. Wilkinson and J.B.A. Millar, unpubl.).

Because expression of pyp2 is dependent upon Atf 1 and because the Pyp2 phosphatase has been shown to be responsible for feedback inhibition of the Styl kinase, then it should follow that in $\Delta a t f 1$ cells activation of Styl is prolonged upon exposure to osmotic stress. To test this prediction, either wild-type cells or $\Delta a t f 1$ cells bearing an epitope-tagged version of Styl were challenged with $0.9 \mathrm{M} \mathrm{KCl}$ and the phosphotyrosine content on the Styl protein was assessed. As shown in Figure 4B, unlike wild-type cells where tyrosine phosphorylation is maximal between 15 and 30 min after exposure but then declines, phosphorylation on Styl remains high in $\Delta a t f 1$ cells. These results show that Atf1 mediates feedback inhibition of the Styl kinase in response to osmotic stress.

Atf1 is required for the induction of gpdl and catalase $m R N A s$ in response to environmental stress

The expression of $g p d 1^{+}$, a gene that encodes glycerol3 -phosphate dehydrogenase required for glycerol biosyn- 
A

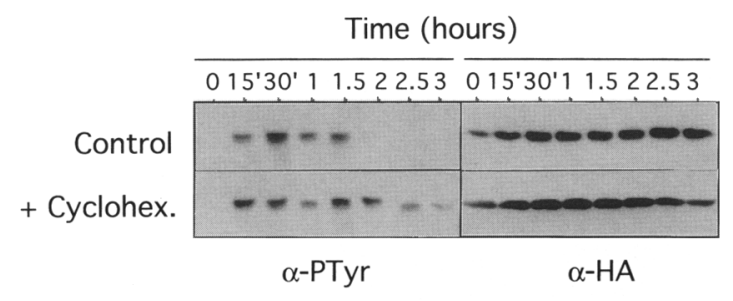

B

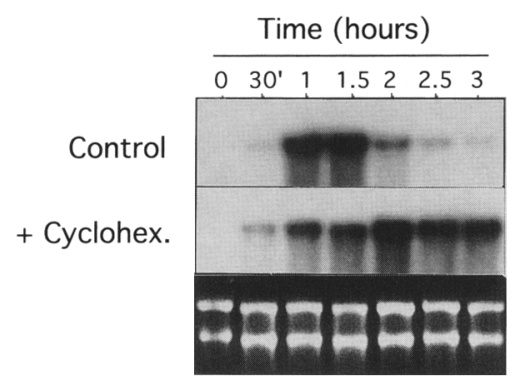

Figure 3. Feedback inhibition of Styl kinase requires protein synthesis. $(A)$ Dephosphorylation of Styl in response to environmental stress requires de novo protein synthesis. Log phase cultures of wild-type cells bearing an epitope-tagged version of the Styl kinase [(pREP41-sty1(HA-6His)] were grown in minimal medium lacking leucine and thiamine either in the presence (+ Cyclohex.) or absence of /Control) of $0.1 \mathrm{mg} / \mathrm{ml}$ cycloheximide for $2 \mathrm{hr}$ and then incubated for the times indicated in the same medium containing $0.9 \mathrm{M} \mathrm{KCl}$. Styl was isolated by $\mathrm{Ni}^{2+}$-NTA affinity precipitation and probed by Western blot for the presence of phosphotyrosine ( $\alpha-\mathrm{PTyr})$ or Hemagglutinin epitope tag $(\alpha-H A)$. (B) Inhibition of protein synthesis inhibits disappearance but not induction of Pyp2 mRNA. Log phase cultures of wild-type cells were grown in minimal medium either in the presence (+ Cyclohex.) or absence of (Control) of 0.1 $\mathrm{mg} / \mathrm{ml}$ cycloheximide for $2 \mathrm{hr}$ and then incubated for the times indicated in the same medium containing $0.9 \mathrm{M} \mathrm{KCl}$. The level of pyp 2 mRNA was assessed by Northern blot analysis using a pyp2 specific probe. Ethidium staining of ribosomal RNA was used to illustrate approximate equal loading in each lane.

thesis, is induced by osmotic stress in a Styl- (M.G. Wilkinson and J.B.A. Millar, unpubl.) and Wisl-dependent (Aiba et al. 1995) manner. We predicted, therefore, that expression of gpd1 ${ }^{+}$would also require Atfl. That this is indeed the case is demonstrated in Figure 5A. Treatment of wild-type cells by the addition of $0.9 \mathrm{M} \mathrm{KCl}$ resulted in a modest increase in gpd1 mRNA levels; the increase was $\sim 3$ - to 5-fold, which corresponds closely to previous observations (Aiba et al. 1995). It is striking that although the stimulation by stress is small in comparison to pyp $2^{+}$, deletion of wis $1^{+}$or atf $1^{+}$results in an almost complete loss in expression (Fig. 5A). This indicated that the uninduced levels of gpd $1^{+}$were also dependent upon the Styl pathway and the Atfl factor.

The catalase gene in fission yeast is induced by osmotic and oxidative stress and by UV radiation (Nakagawa et al. 1995). Since the same signals activate the Styl pathway, we asked whether this factor was involved in catalase expression. As shown in Figure 5B, the induction of catalase mRNA following the addition of $1.2 \mathrm{M}$ sorbitol was lost in $\Delta a t f 1$ cells. Therefore, with respect to the expression of $p y p 2^{+}, g p d 1^{+}$, and catalase, there is a similar dependence on Atf1 and the stressactivated pathway.

As shown previously (Takeda et al. 1995) and in Figure 6A, using the E4 ATF site as a probe, Atfl-dependent complexes can be detected readily by the electrophoretic mobility shift assay (EMSA) following incubation of the probe with whole-cell extracts from wild-type cells. The complex is not seen with extracts from $\Delta a t f 1$ cells and is competed efficiently with unlabeled probe but considerably less well with a probe that has point mutations

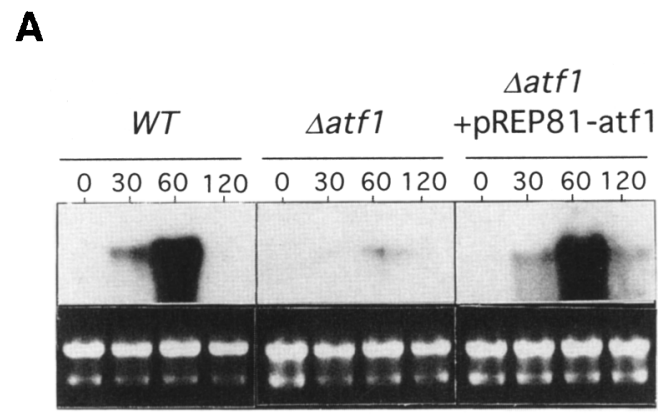

B

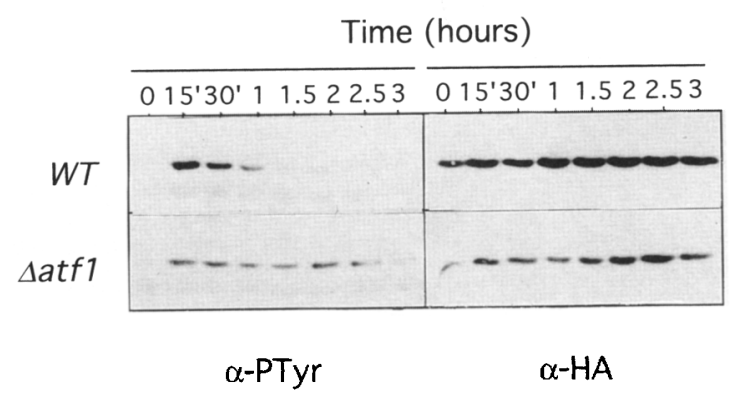

Figure 4. The Atfl transcription factor is required for induction of pyp 2 feedback inhibition of the Styl kinase in response to environmental stress. $(A)$ Induction of the Pyp2 MAP kinase phosphatase requires Atfl. Log phase cultures of either wildtype cells (PR109) bearing the empty vector pREP81 (WT), Datf1

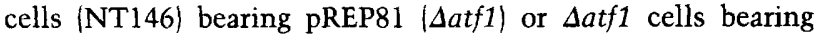
pREP81-atf1 ( $\triangle a t f 1+$ pREP81-atf1) were grown in minimal medium lacking leucine and thiamine and then incubated for the times indicated (in minutes) in the same medium containing 0.9 $\mathrm{M} \mathrm{KCl}$. The level of pyp2 mRNA was assessed by Northern blot analysis using a pyp2 specific probe. Ethidium staining of ribosomal RNA was used to illustrate approximate equal loading in each lane. $(B)$ Feedback inhibition of Styl phosphorylation requires Atf1. Wild-type cells or cells deleted for Atf1 ( $\Delta a t f 1)$ were transformed with an epitope-tagged version of Styl and grown in minimal medium lacking leucine and thiamine at $30^{\circ} \mathrm{C}$. They were then incubated in the same medium containing $0.9 \mathrm{M} \mathrm{KCl}$ for the times indicated. The Styl protein was extracted using $\mathrm{Ni}^{2+}$-NTA agarose beads from the cellular lysates and probed by Western blot for the presence of either phosphotyrosine $\{\alpha$ Ptyr) or hemagglutinin tag $(\alpha-\mathrm{HA})$. 
A

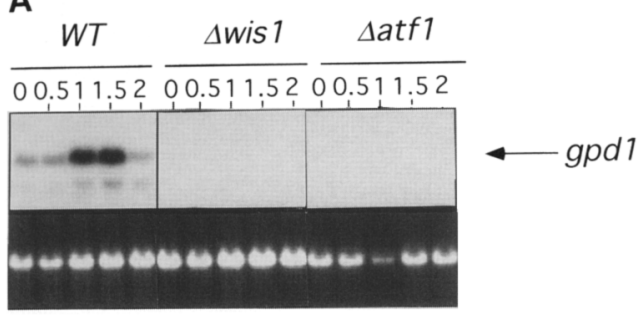

B

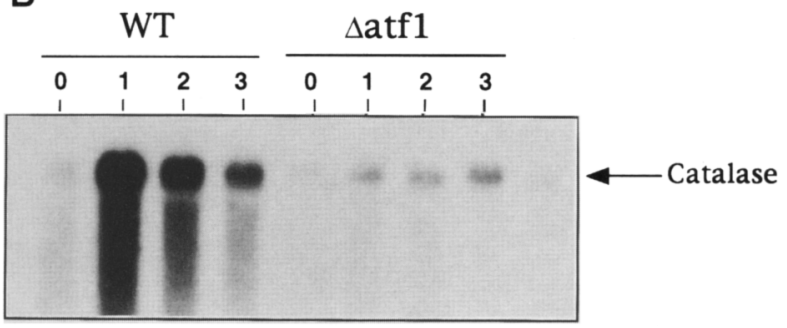

Figure 5. The Atfl factor is required for induction of gpd1 and catalase mRNAs in response to osmotic stress. $(A)$ Log phase cultures of either wild-type cells (PR 109) or $\Delta a t f 1$ cells (NT146) were grown in rich medium and then incubated for the times indicated (in hours) in the same medium containing $0.9 \mathrm{M} \mathrm{KCl}$. The level of gpd1 mRNA was assessed by Northern blot analysis using a gpd1 specific probe. $(B)$ The level of catalase mRNA was assessed by Northern blot analysis using a catalase specific probe as described above, except that osmotic stress was induced with $1.2 \mathrm{M}$ sorbitol.

within the ATF binding sequence (Takeda et al. 1995). Furthermore, there was no significant difference in complex formation with extracts from sorbitol-treated cells, suggesting that activation of Atf 1 does not entail an increase in its DNA binding activity (Fig. 6A). Examination of the sequences upstream of the pyp2 ${ }^{+}, \operatorname{gpd1}{ }^{+}$, and catalase transcriptional start sites revealed the presence of multiple potential Atfl binding sites. In the case of the $g p d 1^{+}$gene, three potential sites are evident at positions -420 to -413 (TTACGTAA), -371 to -364 (TGACGTTT), and -324 to -317 (TTACGTCA) relative to the translation initiation codon. To test whether this upstream region of $g p d 1^{+}$could bind to Atf 1 , EMSA was carried out using a probe extending from -459 to -248 . As shown in Figure 6B, a slow migrating complex was detected with wild-type extracts that was missing with extracts from $\Delta a t f 1$ cells. Again, no difference in the degree of complex formation was seen with extracts from sorbitol-treated cells. These results indicate that Atf 1 can bind to sequences upstream of the $g p d 1^{+}$transcriptional start site, suggesting that the regulation of gpd1 ${ }^{+}$expression by Atf1 is direct.

\section{Atf1 is phosphorylated in vitro by Sty1 kinase}

Taken together, the results described above strongly indicate that the activity of Atf1 is regulated by the Styl/ Wisl signaling pathway. We next addressed whether the link between the pathway and Atfl was direct. Logphase cultures containing an HA-epitope and $\mathrm{His}_{6}$ tagged Styl expressed ectopically from a thiamine-repressible $n m t 1$ promoter were subjected to osmotic stress, and the Styl protein was immunoprecipitated at various times thereafter. Kinase assays were performed with the immunocomplexes using GST-Atfl as a substrate. Atfl was found to be an excellent Styl substrate (Fig. 7A). Efficient phosphorylation was obtained within 15 min of stress treatment; at later time points there was a gradual decrease, in keeping with the transient nature of Styl induction. The presence of multiple phosphorylated species was due to breakdown of the GST-Atfl fusion protein (data not shown). There was no phosphorylation with immunocomplexes isolated from cells treated in the presence of thiamine; under these conditions no Styl protein was synthesized as judged by Western analysis (Fig. 7B).

Recently, a second ATF-like protein in fission yeast has been described to be encoded by the $p c r 1^{+}$gene (Watanabe and Yamamoto 1996). Furthermore, it appears that Atfl and Pcrl can form heterodimers both in vitro and in vivo. Therefore, we tested whether Pcrl was a substrate for Styl using the immunocomplex kinase assay. As shown in Figure 7C, no inducible phosphorylation was seen. In mammalian cells, the stress-activated kinases phosphorylate and activate members of both the

A

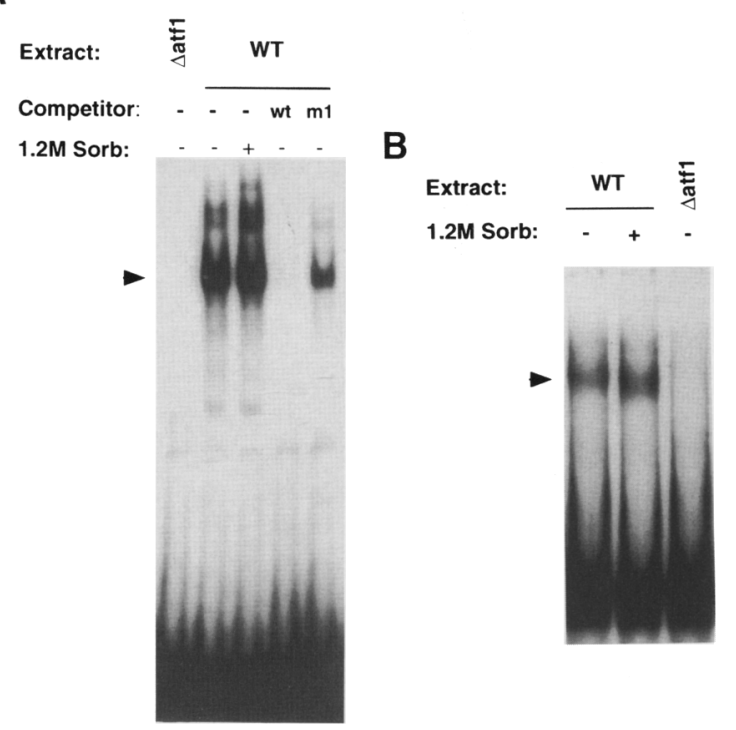

Figure 6. Atf1 binding activity does not change in response to osmotic stress. (A) EMSA was performed with the labeled E4 ATF probe described previously (Takeda et al. 1995) using extracts derived from wild-type (HM123) or $\Delta a t f 1$ (NT146) cells or from wild-type cells incubated in medium containing $1.2 \mathrm{M}$ sorbitol. Where indicated, unlabeled competitor DNAs were added at a molar ratio of 100:1; the competitors were either the oligonucleotides E4ATF (wt) or E4M1 (ml) (Takeda et al. 1995). (B) EMSA was performed as above except that the probe used represented sequences -459 to -248 with respect to the translation initiation site of the gpd1 ${ }^{+}$gene. 
A

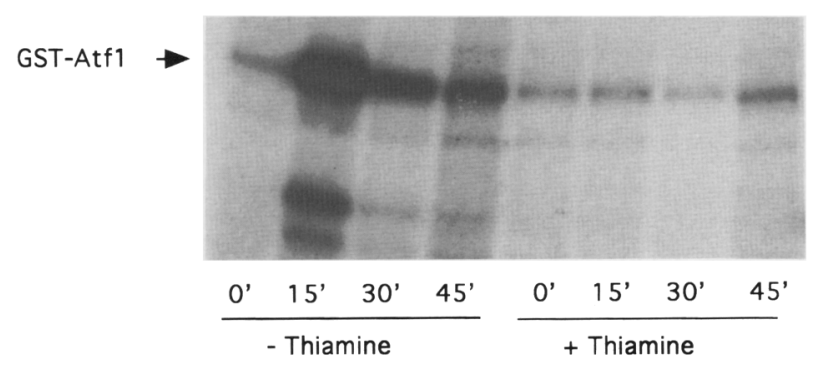

B

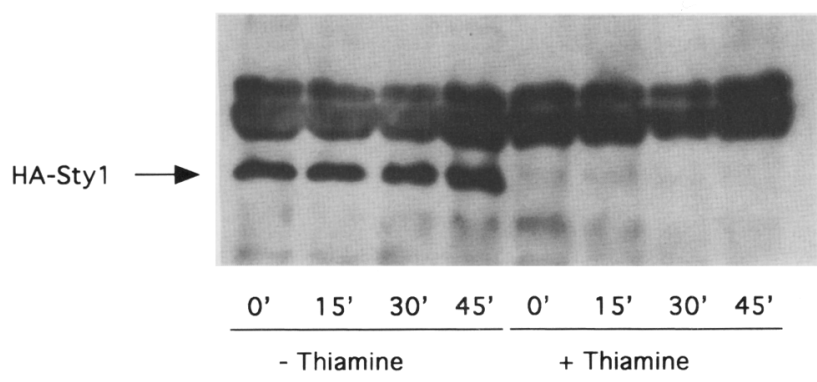

C

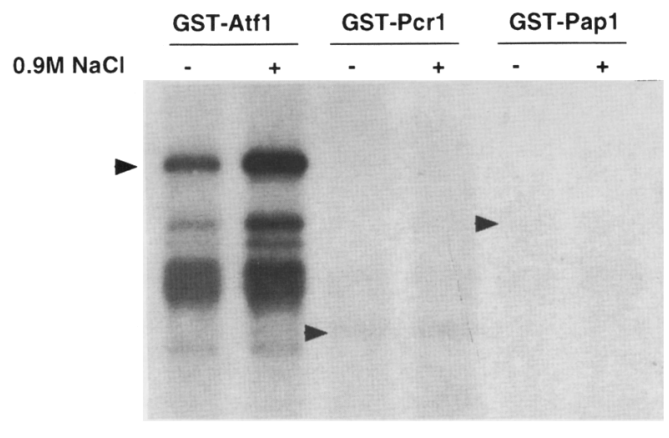

Figure 7. Atfl is phosphorylated by the Styl kinase in vitro. (A) Cells mutated for sty1 (JM1144) were transformed with a

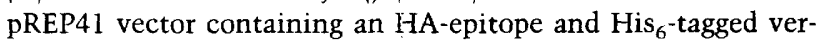
sion of Styl. Expression of the modified Styl is regulated by the thiamine-repressible promoter present in this vector; expression is permissible in the absence but not the presence of thiamine. The transformed cells were grown in minimal medium either lacking or containing thiamine; $\mathrm{KCl}$ was added to a concentration of $0.9 \mathrm{M}$; and aliquots subsequently harvested at the times indicated. Extracts were prepared and Styl protein was immunoprecipitated from each extract using a hemagglutininspecific antibody. The immune complexes were tested for kinase activity using GST-Atfl fusion protein as a substrate. The kinase assays were carried out for $30 \mathrm{~min}$ at $30^{\circ} \mathrm{C}$ and the samples separated by SDS-PAGE and autoradiographed. The arrow indicates the position of the full-length fusion protein. The smaller species represent truncated products of the fusion protein that accumulate following expression in bacteria. $(B)$ The immunoprecipitated complexes described above were assayed directly for the presence of Styl protein by Western analysis using the hemagglutinin-specific antibody. The position of HA$\mathrm{His}_{6}-\mathrm{Sty} \mathrm{l}$ is indicated by the arrow. Expression of the modified Styl protein is repressed in the presence of thiamine. $\{C\}$ Transformed cells containing $\mathrm{HA}-\mathrm{His}_{6}-\mathrm{Styl}$ were grown in the absence of thiamine and aliquots harvested before $(-)$ and $15 \mathrm{~min}$ after $(+)$ the addition of $0.9 \mathrm{M} \mathrm{KCl}$. Extracts were prepared, Styl protein immunoprecipitated, and kinase assays performed as described in Fig. 7A. In addition to GST-Atf1, GST-Pcrl and GST-Pap1 were used as substrates. Only the GST-Atfl fusion was phosphorylated. The arrows indicate the migration position of each of the full-length fusion proteins.

the GST-Atf1 fusion was phosphorylated after preincubation in lysates from stressed cells but not from unstressed cells or cells that were grown in the presence of thiamine and therefore did not express the Styl protein. In addition, the kinase activity that binds to the GSTAtf1 beads is Wis1-dependent (data not shown). These results are consistent with Styl binding to its substrate Atf 1 to form a stable complex in vitro.

A physical interaction between Sty1 and Atf1 was confirmed by two additional assays. The first used the twohybrid assay (Fig. 8B). Styl was fused to the Gal4 DNA binding domain and Atfl to a strong activation domain. Coexpression of the fusion proteins resulted in activation of the Gal4-driven reporter, whereas expression of either alone failed to do so. The second involved the incubation of GST-Atf1 with extracts from cells expressing epitope-tagged Styl followed by Western analysis of bound proteins. As shown in Figure 8C, Styl bound to GST-Atf1 but not to GST alone or a GST fusion containing the carboxy-terminal region of Atfl. 
A
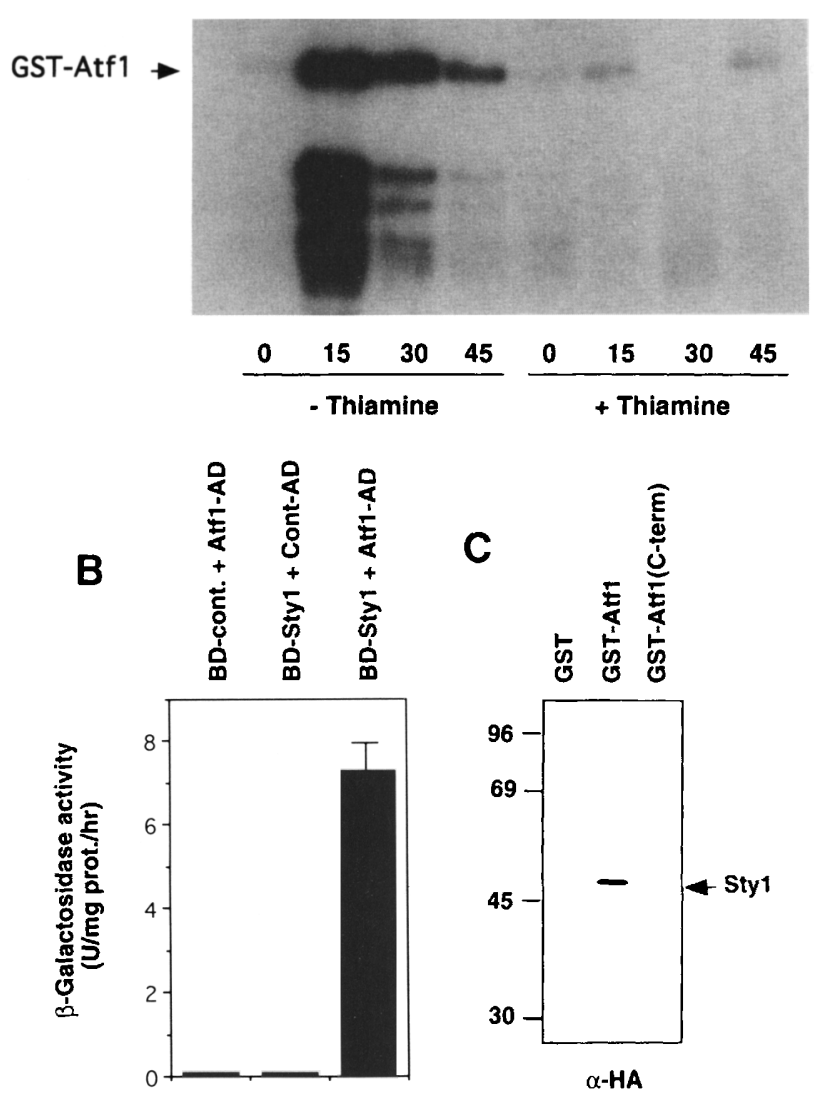

Figure 8. Interaction between Styl and Atfl. (A) sty1 mutant cells (JM1 144) containing HA-His ${ }_{6}-$ Styl as described in Fig. 7A were grown in minimal medium either lacking or containing thiamine to control Styl expression. $\mathrm{KCl}$ was added to a concentration of $0.9 \mathrm{M}$ and aliquots harvested at the times indicated. Extracts were prepared and incubated with GST-Atf 1 protein prebound to GSH-Sepharose beads for $2 \mathrm{hr}$ at $4^{\circ} \mathrm{C}$, as described in Materials and Methods. The beads were extensively washed, kinase reaction buffer added, and a kinase reaction assay allowed to proceed for $30 \mathrm{~min}$ at $30^{\circ} \mathrm{C}$. The phosphorylation of the GST-Atf1 protein was assessed by SDS-PAGE and autoradiography. $(B)$ Two-hybrid analysis of Atf1-Styl interaction. S. cerevisiae strain Y187 was transformed with: (1) pAS-CYH2 expressing the GAL4 DNA binding domain (BDcont.) and pACTII-Atf 1 containing the Atf 1 sequence fused to a strong activation domain (Atf1-AD); or (2) pAS1-CYH2-Styl containing the GAL4 DNA binding domain fused to Styl (BDStyl) and pACTII containing the unfused activation domain(Cont-AD); or (3) pAS1-CYH2-Sty1 and pACTII-Atfl. Expression of a lacZ reporter containing GAL4 binding sites within its promoter was measured by assessing $\beta$-galactosidase activity in extracts as described in Materials and Methods. Measurements are expressed as the mean of three independent determinations (+S.D.) (C) Extracts of wild-type cells expressing HA-tagged Styl were incubated in the presence of $2 \mu \mathrm{g}$ of GST, GST-Atfl la fusion containing full-length Atf1) or GST-Atfl(Cterm) (a fusion containing the carboxy-terminal half of Atfl). After $30 \mathrm{~min}$ at $4^{\circ} \mathrm{C}$, proteins were precipitated with glutathione beads, extensively washed, seperated by SDS-PAGE, and probed for the presence of Sty1 using a monoclonal anti-HA antibody.

\section{Discussion}

Our main conclusion is that the Atfl transcription factor is regulated and directly phosphorylated by the Styl stress-activated kinase. As such, this demonstrates a remarkable degree of conservation between the function of stress-activated MAPK pathways in fission yeast and mammalian cells where the related ATF-2 factor is regulated by SAPK/JNK and p38 kinases. In addition, it represents the first biochemical demonstration in a yeast system of a direct link between a specific transcription factor and an MAPK signaling pathway.

The conclusion is supported by three lines of evidence: (1) There is considerable overlap in the phenotypes that result from the deletion of at 1 or components of the pathway such as sty1 or wis1. Thus in both cases the resulting mutant cells are sterile, defective in survival at stationary phase, hypersensitive to stress, and suppressed in the uncontrolled meiotic induction that normally accompanies loss of Patl kinase activity. (2) The expression of a number of target genes is regulated by both the stress-activated pathway and Atfl. These include the genes $p y p 2^{+}, g p d 1^{+}$, and catalase (this study) and ste $11^{+}$and $f b p 1^{+}$(Takeda et al. 1995; Kato et al. 1996; Stettler et al. 1996). (3) Atf1 is a substrate for the Sty1 kinase in vitro. In addition, it can form a complex with Styl that is sufficiently stable to be detected by the two-hybrid interaction assay and to withstand stringent washing conditions. Such complex formation is a common feature of the mammalian stress-activated MAPKs and their physiologically relevant target proteins.

\section{Regulation of Atf1}

The mechanism by which phosphorylation of Atfl by Styl facilitates Atfl-dependent transcription is presently unknown. An important step will be to identify the sites on Atfl that are phosphorylated by Sty1. Preliminary experiments suggest that multiple phosphorylation sites exist and that the elimination of single sites is not sufficient to render the factor inactive (M. Samuels and $N$. Jones, unpubl.). In the case of the mammalian ATF-2 factor, regulation is mediated at the level of transcription activation; the factor has an activation domain that is stimulated by SAPK/JNK or p38 phosphorylation (Gupta et al. 1995; Livingstone et al. 1995). Current evidence would suggest that it is also the transactivation properties of Atfl that are stimulated by Sty1 phosphorylation, as there is no evidence that either the degree of DNA binding of Atfl or its specificity is altered following induction (Fig. 6B). Recent evidence suggests that Atfl is present in cells as a heterodimer with another bZip protein Pcrl, and deletion of the $p c r 1^{+}$gene results in a phenotype similar to that of $\Delta a t f 1$ cells (Watanabe and Yamamoto 1996). This suggests that it is the heterodimer that is the subject of regulation by the stress-activated pathway. However, Pcrl is not phosphorylated by Styl and so we suggest that it is the Atfl component of the heterodimeric complex that is the target of regulation. It will be important in the future to determine the 
individual activities associated with each of the subunits of the complex. Preliminary evidence indicates that the expression of only a subset of the Atf1-dependent target genes is also dependent upon Pcrl, suggesting differential roles for Atfl homodimeric and Atf1/Pcrl hetrodimeric complexes (W.M. Toone and N. Jones, unpubl.).

\section{Genes that are regulated by Atf1}

A model for the different biological roles that have been attributed to Atfl is presented in Figure 9. At least five different genes that are dependent upon the Atfl factor have now been described (Takeda et al. 1995; this study). In three of these cases $\left(\right.$ ste $11^{+}$, gpd $1^{+}$, and pyp $\left.2^{+}\right)$, activation by stress conditions in a Styl/Wisl-dependent manner has been demonstrated. The known function of the products encoded by these genes helps to explain the defective phenotypes associated with deletion of $a t f 1^{+}$. The sterile phenotype of $\Delta a t f 1$ cells is, at least partially, explained by the loss of expression of the ste $11^{+}$(Takeda et al. 1995/ gene that encodes a transcription factor required for the expression of genes necessary for the sex-

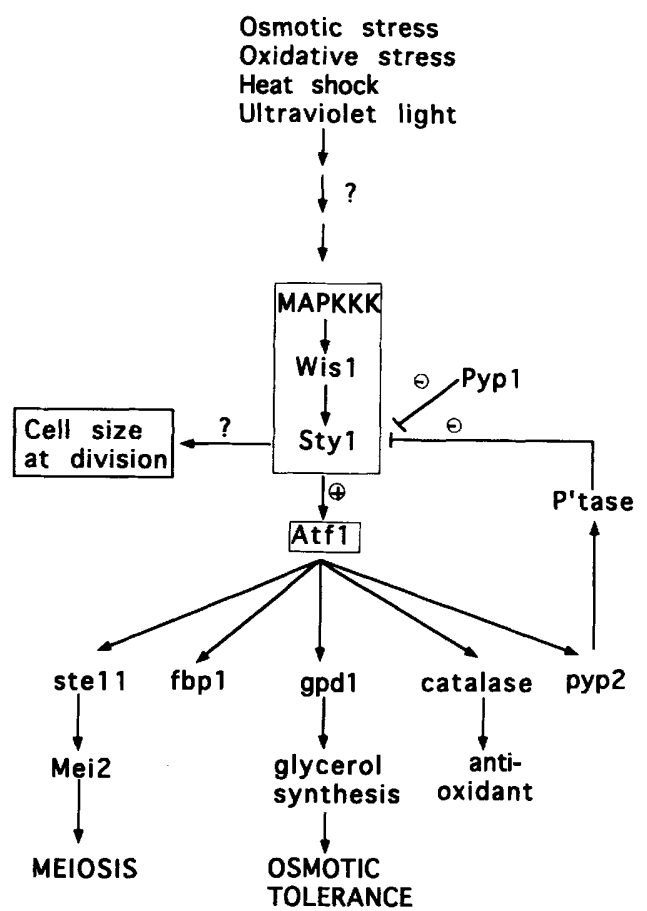

Figure 9. The stress activated Styl kinase pathway in fission yeast. This model depicts the interactions described in this paper and previous reports (Millar et al. 1995; Shiozaki and Russell 1995; Takeda et al. 1995; Degols et al. 1996; Kato et al. 1996; Stettler et al. 1996). Activation of Styl kinase by a signal transduction pathway triggered by numerous stress conditions results in the phosphorylation and activation of the transcription factor Atfl. Active Atfl promotes the transcription of a number of target genes that are involved in the stress response of the cell (gpd1 $1^{+}, f b p 1^{+}$, catalase), in the sexual differentiation pathway (ste $11^{+}$) or in a negative feedback control loop $\left\{\right.$pyp $2^{+}$). ual differentiation pathway. However, it is likely that Atfl plays more than one role in the regulation of this pathway, because ectopic expression of Stell suppresses the conjugation defect of $\Delta a t f 1$ cells without an accompanying increase in spore formation (data not shown). Very similar observations were made in $\Delta$ sty 1 cells expressing ste $11^{+}$from the SV40 promoter (Kato et al. 1996). The additional role of Atfl, therefore, presumably involves the expression of another target required in meiosis.

It is important for cells to maintain intracellular osmolarity in response to changes in the extracellular water potential. One way to accomplish this is to adjust the internal concentrations of an osmolyte such as glycerol. The gpd $1^{+}$gene is involved in the synthesis of glycerol, and its expression has been shown to be important for the response of the cell to high osmolarity conditions. The dependence on Atfl of its expression explains why $\Delta a t f 1$ cells are osmosensitive. The expression of gpd1 is induced upon osmotic shock. The level of induction, however, is rather modest (three- to fivefold), because of a relatively high level of basal, uninduced expression; nevertheless, this basal expression is dependent upon Atfl and Wis1. This may reflect a persistent basal level of signaling through the Sty $1 /$ Wisl pathway that can be activated acutely upon imposition of stress.

Both the $\Delta s t y 1$ (Degols et al. 1996) and $\Delta a t f 1$ (data not shown) cells are mildly sensitive to oxidative stress. This phenotype is very likely explained by the requirement of the Sty1/Wisl pathway and the Atfl factor for the induced expression of the catalase gene following a variety of stress conditions. Catalase is a potent free-radical scavenger and plays an important role in the protection of cells against oxidant injury. Accordingly, the induction of catalase activity by $\mathrm{H}_{2} \mathrm{O}_{2}$ is a common feature of yeast and mammalian cells.

The pyp $2^{+}$gene is another important downstream target of the Styl kinase and the Atfl factor and is responsible, at least in part, for feedback inhibition of the Sty 1 pathway by the Pyp 2 tyrosine-specific phosphatase. As a result, down-regulation of Styl kinase activity observed normally on prolonged exposure to osmotic stress is lost in $\Delta a t f 1$ cells. One caveat is that the Sty 1 kinase is overexpressed in these experiments and that the stoichiometric quantity of MAP kinase phosphatase relative to MAP kinase may be important for the timing of inactivation. Nevertheless, we believe this provides the first full example of a feedback loop controlling an MAPK pathway to be described. Considerable attention has been focused on the mechansims of MAPK pathway activation, whereas relatively little is known of the mechansims by which the signal is attenuated, despite the fact that the duration of signal flow through the cascade may be critical for the ultimate cellular response. Indeed, more recent experiments have uncovered Pyp2and Atfl-independent mechanisms operating to attenuate signaling through the Styl pathway that are yet uncharacterized (Degols et al. 1996; M.G. Wilkinson and J.B.A. Millar, unpubl.).

Although to date many of the targets that we have 
identified as being Atf1-dependent are also dependent upon the Styl/Wisl pathway, there are likely to be additional targets regulated by the pathway but independent of Atfl. This conclusion comes from the observation that $\Delta a t f 1$ cells do not display any cell size at division defect and show no synthetic interaction with cdc25-22 cells; both phenotypes are associated with loss of Styl or Wisl. Therefore, the control of the initiation of mitosis by the Styl pathway cannot be explained by its control of Atfl activity. Perhaps a different transcription factor controlled by Styl is involved.

\section{Regulation of ATF activity by stress-activated MAPK pathways is conserved}

Atf1 shows homology to the mammalian factor ATF-2 (Takeda et al. 1995). This homology is almost entirely restricted to the bZip domain; it would appear to be significant because it is greater than the sequence similarity seen between bZip domains of many of the different mammalian members of the ATF family. The activity of ATF-2 is regulated by the stress-activated MAPK pathways through the phosphorylation of critical threonine residues in the amino-terminal activation domain (Gupta et al. 1995; Livingstone et al. 1995). Our finding that Atf 1 is regulated by the equivalent pathway in fission yeast highlights a remarkable level of conservation in the function of the stress-activated pathways. Although it has been clear for some time that the signaling pathways in yeast and mammalian cells show a degree of conservation, this is the first time that the conservation extends to a downstream transcription factor target. It would appear, therefore, that the Atfl factor is both a structural and functional homolog of ATF-2, and, indeed, preliminary experiments indicate that ectopic expression of ATF-2 in $\Delta a t f 1$ cells results in partial suppression of the defective mating phenotype (T. Takeda and $\mathrm{N}$. Jones, unpubl.). It should be noted, however, that outside of the bZip domain there is no obvious homology between the two factors. In particular, features of the mammalian ATF-2 transactivation domain such as the zincfinger and kinase interaction domain cannot be found in Atfl. This may mean that the two factors are regulated differently even though they both require the stress-sig- naling pathway. On the other hand, it may mean that there are common features that are difficult to recognize until careful structure and function analyses have been carried out. Support for this possibility comes from a comparison of the ATF-2 and cJun factors. Outside of the binding domain, very little homology is apparent. Yet it is now clear that they both contain activation domains that are regulated in a similar fashion; they are dependent upon phosphorylation by stress-activated MAPKs and contain a region involved in stable complex formation with these kinases. Furthermore, ATF-2 has a Hob1-like motif that has been shown to be an important component of the clun activation domain, and mutations within this motif of ATF- 2 cripple its activity (A. Clark and N. Jones, unpubl.). Thus ATF-2 and cJun clearly overlap at the functional level despite the fact that there is little similarity at the primary amino acid sequence level. We suggest that a similar situation may exist between ATF- 2 and Atf1.

The situation appears to be quite different in the budding yeast $S$. cerevisiae. An element has been identified (STRE) that mediates the activation of many genes in response to a variety of stress conditions including osmotic and oxidative stress. This element, however, is not an ATF binding site, and two recently described factors that recognize and bind to it are zinc-finger-containing proteins rather than bZip proteins (Martinez-Pastor et al. 1996). One budding yeast bZip-containing factor that does play a significant role in stress response is the Yaplp activator, which mediates the induction of certain genes by oxidative stress (Ruis and Schuller 1995). However, this factor is homologous to the fission yeast factor Pap1 rather than Atf1; the DNA binding specificities of Papl and Atfl are clearly different. Furthermore, the Sty 1 homolog in budding yeast, Hoglp, is activated by osmotic stress only, and so it appears that the HOG pathway, unlike the Styl pathway in fission yeast or the JNK/SAPK or p38 pathways in mammalian cells, is not a general stress-signaling pathway. Therefore, with respect to the signaling pathways and the transcription factors that are involved in the stress response, it appears that fission yeast more closely resembles what has been observed in mammalian cells. As such it offers a useful model for studying these stress-related events.

Table 2. Strains used in this study

\begin{tabular}{|c|c|c|}
\hline $\begin{array}{l}\text { Strain } \\
\text { no. }\end{array}$ & Genotype & Reference/source \\
\hline HM 123 & $h^{-}$leu-32 & Our stock \\
\hline PR 109 & $h^{-1 e u 1-32 u r a 4-D 18}$ & P. Russell (The Scripps Research Institute, La Jolla, CA) \\
\hline NT146 & $h^{-}$leu1-32ura4-D18atf1::ura4 ${ }^{+}$ & Takeda et al. 1995 \\
\hline JM544 & $h^{-}$leu1-32ura4-D18wis1::ura4 ${ }^{+}$ & Millar et al. 1995 \\
\hline JM1 144 & $h^{-}$sty1-1leu1-32ura4-D18 & Millar et al. 1995 \\
\hline SOP13 & $h^{-}$leu1-32ura4-D18ade6-216pyp1::ura4 ${ }^{+}$ & P. Russell (The Scripps Research Institute, La Jolla, CA) \\
\hline JM 836 & $h^{-}$leu1-32 ura4-D18 pat1-114 & This study \\
\hline JM 1266 & $h^{-}$leu1-32 ura4-D18 wis1::ura4 ${ }^{+}$pat $1-114$ & This study \\
\hline JM 1267 & $h^{-}$leu1-32 ura4-D18 sty1::urta4 ${ }^{+}$pat1-114 & This study \\
\hline JM1352 & $h^{-1 e u 1-32 u r a 4-D 18 a d e 6-M 210 c d c 25-22}$ & This study \\
\hline
\end{tabular}




\section{Materials and methods}

Yeast strains, media, and general methods

The yeast strains used in this study are described in Table 2. Media and general experimental methods have been described elsewhere (Moreno et al. 1991; Alfa et al. 1993).

\section{Plasmids}

To express various GST proteins, the plasmids pGST-Atf1, pGST-Atfl(C-term), pGST-Pcrl and GST-Papl were constructed by inserting PCR-generated fragments containing fulllength Atfl, Pcrl, or Papl or truncated Atfl (amino acids 286586 ) into the vector pGEX-KG (Guan and Dixon 1991). The proteins were expressed and purified on glutathione-agarose beads as described previously (Guan and Dixon 1991). For the two-hybrid interaction assay, full-length Styl and Atfl sequences were cloned into the vectors pAS1-CYH2 and PACTII, respectively (Durfee et al. 1993).

\section{RNA isolation and hybridization}

The isolation of mRNA and subsequent Northern analysis was performed as described previously (Millar et al. 1995). A 1-kb EcoRV fragment from pGEM-3Z-pyp2 was used to probe for pyp2 mRNA (Millar et al. 1995), a 1.1-kb EcoRI fragment was used to probe for gpd1 mRNA (Pidoux et al. 1990), and a 1.5-kb PCR-derived fragment covering the whole open reading frame was used to probe for catalase mRNA (Nakagawa et al. 1995).

\section{Sty1 kinase assays}

$\Delta$ Sty1 cells containing the plasmid pRep41 HA/6xHis styl (Millar et al. 1995) were grown in EMM containing $75 \mu \mathrm{g} / \mathrm{ml}$ uracil, and where indicated, $2 \mu \mathrm{M}$ thiamine until they reached midlog phase. Then $40 \mathrm{ml}$ of cells were mixed with either $17 \mathrm{ml}$ fresh (Edinburgh minimal medium (EMM) or EMM containing 3 $\mathrm{M} \mathrm{KCl}$ and incubated for the appropriate length of time. The cells were rapidly cooled and harvested $4^{\circ} \mathrm{C}$. The resulting pellets were washed with ice-cold $\mathrm{H}_{2} \mathrm{O}$ and resuspended with $40 \mu \mathrm{l}$ of lysis buffer [ $20 \mathrm{~mm}$ Tris $(\mathrm{pH} 8.0\}, 137 \mathrm{~mm} \mathrm{NaCl}, 15 \%$ glycerol, $0.1 \%$ TritonX-100, $1 \mathrm{~mm}$ DTT, $5 \mathrm{~mm}$ EDTA, $1 \mathrm{~mm}$ PMSF, 10 $\mu \mathrm{g} / \mathrm{ml}$ aprotinin, $10 \mathrm{~g} / \mathrm{ml}$ leupeptin, $1 \mathrm{~mm}$ EGTA, $1 \mathrm{~mm}$ tetrasodium pyrophosphate, $100 \mathrm{~mm}$ beta-glycerophosphate, $10 \mathrm{~mm}$ $\mathrm{NaF}$, and $1 \mathrm{~mm}$ sodium orthovanadate] and broken by vortexing with $1 \mathrm{ml}$ of chilled acid-washed glass beads. The resulting supernatant was removed and assayed for protein concentration by use of the Bio-Rad Protein Assay Kit.

For the immunecomplex kinase assay, $170 \mu \mathrm{g}$ of lysate was incubated with $5 \mu \mathrm{l}$ of monoclonal anti-HA antibody for $\mathrm{l} \mathrm{hr}$ at $4^{\circ} \mathrm{C}$. Then $20 \mu \mathrm{l}$ of protein G-Sepharose (dry volume) was added for an additional $1 \mathrm{hr}$. The beads were collected, and washed $3 \times$ with $400 \mu \mathrm{l}$ of lysis buffer. Then $2 \mu \mathrm{g}$ of GST-Atf1 protein was added in wash buffer. The buffer was removed and $20 \mu \mathrm{l}$ of kinase reaction buffer $[20 \mathrm{mM}$ HEPES (pH 7.5), $20 \mathrm{mM} \mathrm{MgCl}, 2$ mM DTT, $20 \mu \mathrm{M}$ ATP, $\left.5 \mu \mathrm{Ci}\left[\gamma^{-32} \mathrm{P}\right] \mathrm{ATP}\right]$ was added. The reaction was carried out for $30 \mathrm{~min}$ at $30^{\circ} \mathrm{C}$ and stopped by adding 5 $\mu l$ of $5 \times$ Lammeli buffer and heated to $95^{\circ} \mathrm{C}$ for $5 \mathrm{~min}$. Samples were then run on $10 \%$ PAGE gels, transferred onto PVDF membranes, and autoradiographed.

For the binding kinase assay, $300 \mu \mathrm{g}$ of lysate was incubated with $2 \mu \mathrm{g}$ of GST-Atfl protein prebound to glutathione-Sepharose for $2 \mathrm{hr}$ at $4^{\circ} \mathrm{C}$. The beads were collected, washed $3 \times$ with $400 \mu \mathrm{l}$ lysis buffer, and $20 \mu \mathrm{l}$ kinase reaction buffer $[20 \mathrm{mM}$ HEPES (pH 7.5), $20 \mathrm{~mm} \mathrm{MgCl}_{2}, 2 \mathrm{mM}$ DTT, $20 \mu \mathrm{M}$ ATP, $5 \mu \mathrm{Ci}$ $\left.\left[\gamma^{32} \mathrm{P}\right] \mathrm{ATP}\right]$ was added. The reaction was for $30 \mathrm{~min}$ at $30^{\circ} \mathrm{C}$ and was stopped by adding $5 \mu$ l of $5 \times$ Lammeli buffer and heated to $95^{\circ} \mathrm{C}$ for $5 \mathrm{~min}$. Samples were then run on $10 \%$ PAGE gels, transferred onto PVDF membranes, and autoradiographed.

\section{Western blot analysis}

The PVDF membranes were blocked for $1 \mathrm{hr}$ with $3 \%$ BSA containing $0.1 \%$ (vol/vol) Tween 20 . Anti-HA antibody was added at $1 / 1000$ dilution in blocking buffer for $1 \mathrm{hr}$ and the blot was washed $3 \times$ for $15 \mathrm{~min}$ with TBS plus $0.5 \%$ NP40. Antimouse HRP at $1 / 10000$ was applied for $1 \mathrm{hr}$ and the blot was washed $3 \times$ for $15 \mathrm{~min}$. ECL (Amersham) was performed to visualize the bound antibody.

\section{Electrophoretic mobility shift assay}

Cells were grown to mid-log phase, harvested, washed with $1 \mathrm{ml}$ of $\mathrm{H}_{2} \mathrm{O}$, resuspended in $40 \mu \mathrm{l}$ of lysis buffer $25 \mathrm{mM}$ HEPES ( $\mathrm{pH}$ 7.6), $0.1 \mathrm{~mm}$ EDTA, $150 \mathrm{~mm} \mathrm{KCl}, 0.1 \%$ TritonX100, 25\% Glycerol, $1 \mathrm{~m}$ urea, $1 \mathrm{mM}$ DTT, $1 \mathrm{~mm}$ PMSF, $10 \mu \mathrm{g} / \mathrm{ml}$ aprotinin, 10 $\mu \mathrm{g} / \mathrm{ml}$ leupeptin, $1 \mathrm{mM}$ EGTA, $1 \mathrm{~mm}$ tetrasodium pyrophosphate, $100 \mathrm{~mm} \beta$-glycerophosphate, $10 \mathrm{~mm} \mathrm{NaF}$, and $1 \mathrm{~mm}$ sodium orthovanadate] and lysed as above. Then $30 \mu \mathrm{g}$ lysate was incubated in $20 \mu \mathrm{l}$ binding buffer containing 25 mMHEPES ( $\mathrm{pH}$ $7.6), 34 \mathrm{mM} \mathrm{KCl}, 5 \mathrm{mM} \mathrm{MgCl}_{2}$, and $2 \mu \mathrm{g}$ of poly[d(I-C)] for $10 \mathrm{~min}$ at room temperature, and then for $20 \mathrm{~min}$ with $1 \mathrm{ng}^{32} \mathrm{P}$-labeled probe. Reactions were run out on a $4 \%$ acrylamide gel in $0.5 \mathrm{M}$ $\mathrm{TBE}$, dried down, and exposed for autoradiography.

\section{Two-hybrid interaction assay}

The atfl gene was amplified by PCR using the $5^{\prime}$ oligonucleotide 5'-ACATACCATGGCATCCCCGTCTCCCGTCAATACTTCCA-3' incorporating an NcoI site (shown italicized) and the 3' oligonucleotide 5'-ACGTCTCGAGAGATCAAAAACAGTCTAGTACCT -3 ' incorporating a Xhol site (shown italicized) to produce a 1734-bp fragment that was digested with $\mathrm{NcOI}$ and $\mathrm{XhOI}$ and ligated into the $\mathrm{NCOI}$ and $\mathrm{Xhol}$ sites of pACTII (Durfee et al. 1993) to form pACTII-atf 1 expressing a fusion protein of the GAL4 activation domain with the atfl ORF under the control of the adh promoter. The plasmid pRep4lHA/6xHis styl (Millar et al. 1995) was digested with NdeI and BamHI and a fragment containing the styl ORF ligated into the NdeI and BamHI sites of pAS1-CYH2 (Durfee et al. 1993) to form pAS1CYH2-Sty1. Expression of both fusion proteins in $S$. cerevisiae strain Y187 (Durfee et al. 1993) was verified by Western blot using a monoclonal antibody to the hemaglutinin tag (12CA5).

\section{Acknowledgments}

We thank Lee Johnston, Steve Sedgwick, Richard Treisman, and members of the Division of Yeast Genetics (National Institute for Medical Research) and Laboratory of Gene Regulation [Imperial Cancer Research Fund (ICRF)] for helpful advice and discussions and Paul Russell for strains. This research was supported by the ICRF (N.J. and T. Toda.), the Medical Research Council (J.B.A.M.), and the Human Frontier Science Program Organization (N.J.).

The publication costs of this article were defrayed in part by payment of page charges. This article must therefore be hereby marked "advertisement" in accordance with 18 USC section 1734 solely to indicate this fact. 


\section{References}

Aiba, H., H. Yamada, R. Ohmiya, and T. Mizuno. 1995. The osmoinducible gpdl ${ }^{+}$gene is a target of the signaling pathway involving Wis1 MAP-kinase kinase in fission yeast. FEBS Lett. 376: 199-201.

Alfa, C., P. Fantes, J. Hyams, M. McLeod, and E. Warbrick. 1993. Experiments with fission yeast. Cold Spring Harbor Laboratory Press, Cold Spring Harbor, N.Y.

Ammerer, G. 1994. Sex, stress and integrity: The importance of MAP kinase pathways in yeast. Curr. Opin. Genet. Dev. 4: 90-95.

Brewster, J.L., T. de Valoir, N.D. Dwyer, E. Winter, and M.C. Gustin. 1993. An osmosensing signal transduction pathway in yeast. Science 259: 1760-1763.

Davies, R.J. 1994. MAPKs: A new JNK expands the group. Trends Biochem. Sci. 19: 470-473.

Degols, G., K. Shiozaki, and P. Russell. 1996. Activation and regulation of the Spcl stress-activated protein kinase in Schizosaccharomyces pombe. Mol. Cell Biol. 16: 2870 2877.

Derijard, B., M. Hibi, I.H. Wu, T. Barrett, B. Su, T. Deng, M. Karin, and R.J. Davies. 1994. JNKI: A protein kinase stimulated by UV light and Ha-Ras that binds and phosphorylates the c-Jun activation domain. Cell 76: 1025-1037.

Durfee, T., K. Becherer, P.-L. Chen, S.-H. Yeh, Y. Yang, A. Kilburn, W.-H. Lee, and S.J. Elledge. 1993. The retinoblastoma protein associates with the protein phosphatase type 1 catalytic subunit. Genes \& Dev. 7: 555-569.

Freshney, N.W., L. Rawlinson, F. Guesdon, E. Jones, S. Cowley, J. Hsuan, and J. Saklatvala. 1994. Interleukin-1 activates a novel protein kinase cascade that results in the phosphorylation of hsp27. Cell 78: 1039-1049.

Gille, H., T. Strahl, and P.E. Shaw. 1995. Activation of ternary complex factor elk-1 by the stress-activated protein kinases. Curr. Biol. 5: 1191-1200.

Guan, K.L. and J.E. Dixon. 1991. Eukaryotic proteins expressed in Escherichia coli: an improved thrombin cleavage and purification procedure of fusion proteins with glutathione S-transferase. Anal. Biochem. 192: 262-267.

Gille, H., A.D. Sharrocks, and P.E. Shaw. 1992. Phosphorylation of transcription factor $\mathrm{p} 62^{\mathrm{TCF}}$ by MAP kinase stimulates ternary complex function at the $\mathrm{c}$-fos promoter. Nature 358: $414-417$.

Gupta, S., D. Campbell, B. Derijard, and R.J. Davies. 1995. Transcription factor ATF2 regulation by the JNK signal transduction pathway. Science 267: 389-393.

Han, J., J.-D. Lee, L. Bibbs, and R.L. Ulevitch. 1994. A MAP kinase targeted by endotoxin and hyperosmolarity in mammalian cells. Science 265: 808-811.

Herskowitz, I. 1995. MAP kinase pathways in yeast: For mating and more. Cell 80: 187-197.

Hibi, M., A. Lin, T. Smeal, A. Minden, and M. Karin. 1993. Identification of an oncoprotein- and UV-responsive protein kinase that binds and potentiates the c-Jun activation domain. Genes \& Dev. 7: 2135-2148.

Iino, Y. and M. Yamamoto. 1985a. Mutants of Schizosaccharomyces pombe which sporulate in the haploid state. Mol. Gen. Genet. 118: 416-421.

- 1985b. Negative control for the initiation of meiosis in Schizosaccharomyces pombe. Proc. Natl. Acad. Sci. 82: 2447-2451.

Kato, T., K. Okazaki, H. Murakami, S. Stettler, P. Fantes, and H. Okayama. 1996. Stress signal, mediated by a HOGl-like MAP kinase, controls sexual development in fission yeast. FEBS Lett. 378: 207-212.
Kyriakis, J.M., P. Baneriee, E. Nikolakaki, T. Dai, E.A. Rubie, M.F. Ahmad, J. Avruch, and J.R. Woodgett. 1994. The stressactivated protein kinase subfamily of c-Jun kinases. Nature 369: 156-160.

Kuge, S. and N. Jones. 1994. YAP1 dependent activation of TRX2 is essential for the response of Saccharomyces cerevisiae to oxidative stress by hydroperoxides. EMBO I. 13: 655664.

Lee, J.C., J.T. Laydon, P.C. McDonnell, T.F. Gallagher, S. Kumar, D. Green, D. McNulty, M.J. Blumenthal, J.R. Heys, S.W. Landvatter, J.E. Strickler, M.M. McLaughlin, I.V. Siemens, S.M. Fisher, G.P. Livi, J.R. White, J.L. Adams, and P.R. Young. 1994. A protein kinase involved in the regulation of inflammatory cytokine biosynthesis. Nature 372: 739-746.

Levin, D.E. and B. Errede. 1995. The proliferation of MAP kinase signaling pathways in yeast. Curr. Opin. Cell Biol. 7: 197202.

Livingstone, C., G. Patel, and N. Jones. 1995. ATF-2 contains a phosphorylation-dependent transcriptional activation domain. EMBO J. 14: 1785-1797.

Marais, R., J. Wynne, and R. Treisman. 1993. The SRF accessory protein Elkl contains a growth factor-regulated transcriptional activation domain. Cell 73: 381-393.

Marshall, C.J. 1994. MAP kinase kinase kinase, MAP kinase kinase, and MAP kinase. Curr. Opin. Genet. Dev. 4: 82-89.

Martinez-Pastor, M.T., G. Marchler, C. Sculler, A. MarchlerBauer, H. Ruis, and F. Estruch. 1996. The Saccharomyces cerevisiae zinc finger proteins $\mathrm{Msn} 2 \mathrm{p}$ and Msn4p are required for transcriptional induction through the stress- response element (STRE). EMBO I. 15: 2227-2235.

Maundrell, K. 1993. Thiamine-repressible expression vectors pREP and pRIP for fission yeast. Gene 123: 127-130.

Millar, J.B.A., P. Russell, J.E. Dixon, and K.L. Guan. 1992. Negative regulation of mitosis by two functionally overlapping PTPases in fission yeast. EMBO I. 11: 4943-4952.

Millar, J.B.A., V. Buck, and M.G. Wilkinson. 1995. Pyp1 and pyp2 PTPases dephosphorylate an osmosensing MAP kinase controlling cell size at division in fission yeast Genes $\&$ Dev. 9: 2117-2130.

Moreno, S., A. Klar, and P. Nurse. 1991. Molecular genetic analysis of fission yeast Schizosaccharomyces pombe. Method. Enzymol. 194: 795-823.

Nakagawa, C.W., N. Mutoh, and Y. Hayashi. 1995. Transcriptional regulation of catalase gene in the fission yeast Schizosaccharomyces pombe: Molecular cloning of the catalase gene and northern blot of the transcript. $J$. Biochem. 118: 109-116.

Pidoux, A.L., E.H. Fawell, and J. Armstrong. 1990. Glycerol-3phosphate dehydrogenase homologue from Schizosaccharomyces pombe. Nucleic Acids Res. 18: 7145.

Raingeaud, J., S. Gupta, J.S. Rogers, M. Dickens, J. Han, R.J. Ulevitch, and R.J. Davies. 1995. Pro-inflammatory cytokines and environmental stress cause p38 mitogen-activated protein kinase activation by dual phosphorylation on tyrosine and threonine. J. Biol. Chem. 270: 7420-7426.

Rouse, J., P. Cohen, S. Trigon, M. Morange, A. Alonso-Llamazares, D. Zamanillo, T. Hunt, and A. Nebrada. 1994. A novel kinase cascade triggered by stress and heat shock that stimulates MAPKAP kinase- 2 and phosphorylation of the small heat shock proteins. Cell 78: 1027-1037.

Ruis, H. and C. Schuller. 1995. Stress signaling in yeast. BioEssays 17: 959-965.

Shiozaki, K. and P. Russell. 1995. Cell cycle control linked to extracellular environment by MAP kinase pathway in fission yeast. Nature 378: 739-743.

Stettler, S., E. Warbrick, S. Prochnik, S. Mackie, and P. Fantes. 
1996. The wisl signal transduction pathway is required for expression of cAMP-repressed genes in fission yeast. I. Cell Sci. 109: 1927-1935.

Sugimoto, A., Y. Iino, Y. Watanabe, and M. Yamamoto. 1991. Schizosaccharomyces pombe ste $11^{+}$encodes a transcription factor with an HMG motif that is a critical regulator of sexual development. Genes \& Dev. 5: 1990-1999.

Takeda, T., T. Toda, K. Kominami, A. Kohnosu, M. Yanagida, and N. Jones. 1995. Schizosaccharomyces pombe atf $1^{+}$encodes a transcription factor required for sexual development and entry into stationary phase. EMBO J. 14: 6193-6208.

Toda, T., M. Shimanuki, amd M. Yanagida. 1991. Fission yeast genes that confer resistence to staurosporine encode an APllike transcription factor and a protein kinase related to the mammalian ERK1/MAP2 and budding yeast FUS3 and KSS1 kinases. Genes \& Dev. 5: 60-73.

Treisman, R. 1996. Regulation of transcription by MAP kinase cascades. Curr. Opin. Cell Biol. 8: 205-215.

van Dam, H., D. Wilhelm, I. Herr, A. Steffen, P. Herrlich, and P. Angel. 1995. ATF-2 is preferentially activated by stress-activated protein kinases to mediate $\mathrm{c}$-jun induction in response to genotoxic agents. EMBO I. 14: 1798-1811.

Warbrick, E. and P. Fantes. 1991. The Wisl protein kinase is a dose-dependent regulator of mitosis in Schizosaccharomyces pombe. EMBO I. 10: 4291-4299.

Wasiewicz, A.J. and J.A. Cooper. 1995. Mitogen and stress response pathways: MAP kinase cascades and phosphatase regulation in mammals and yeast. Curr. Opin. Cell. Biol. 7: 798-805.

Watanabe, Y. and M. Yamamoto. 1996. Schizosaccharomyces pombe $\mathrm{cr}^{+}$encodes a CREB/ATF protein involved in regulation of gene expression for sexual development. Mol. Cell Biol. 16: 704-711.

Whitmarsh, A.J., P. Shore, A.D. Sharrocks, and R.J. Davies. 1995. Integration of MAP kinase signal transduction pathways at the serum response element. Science 269: 403-407.

Zinck, R., M.A. Cahill, M. Kracht, C. Sachsenmaier, R.A. Hipskind, and A. Nordheim. 1995. Protein synthesis inhibitors reveal differential regulation of mitogen-activated proteinkinase and stress-activated protein kinase pathways that converge on elk-1. Mol. Cell. Biol. 15: 4930-4938. 


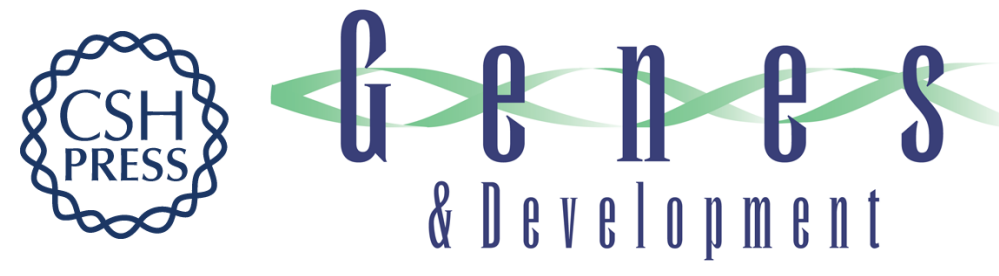

\section{The Atf1 transcription factor is a target for the Sty1 stress-activated MAP kinase pathway in fission yeast.}

M G Wilkinson, M Samuels, T Takeda, et al.

Genes Dev. 1996, 10:

Access the most recent version at doi:10.1101/gad.10.18.2289

References This article cites 47 articles, 15 of which can be accessed free at:

http://genesdev.cshlp.org/content/10/18/2289.full.html\#ref-list-1

License

Email Alerting

Service

Receive free email alerts when new articles cite this article - sign up in the box at the top right corner of the article or click here.

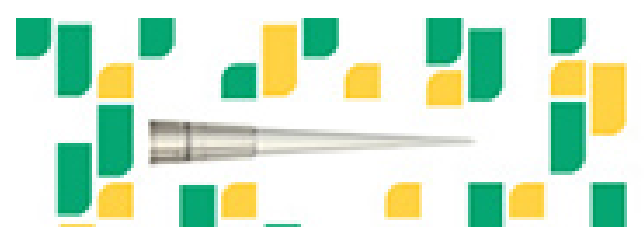

Focused on your science.

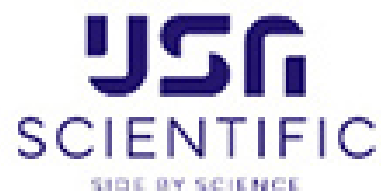

Copyright (c) Cold Spring Harbor Laboratory Press 